\title{
Primary subcutaneous implantation hydatid cyst
}

A 70-year-old female patient presented with subcutaneous cystic swelling following cholecystectomy. The patient underwent surgery and was eventually diagnosed as having hydatid cyst $(\mathrm{HC})$. Primary subcutaneous $\mathrm{HC}$ is rare, but primary implantation $\mathrm{HC}$ is unknown. This report is an index case of such an entity.

Key words: Hydatid cyst, implantation, soft tissue, subcutaneous

\section{INTRODUCTION}

Hydatid cyst (HC) is a parasitic infestation caused by the larval form of Echinococcus granulosus (EG). ${ }^{[1]}$ The definitive hosts for EG are dogs, wolves, and foxes; while intermediate hosts include sheep, goats, and cattle. Humans are a coincidental (accidental) intermediate host. ${ }^{[2]}$ The disease is more frequent in sheep rearing countries of the Middle East, Central Europe, Australia, and South America. ${ }^{[1,2]}$ The commonest organs affected are the liver $(70 \%)$ and lungs $(10-15 \%) \cdot{ }^{[1-3]}$ Other locations are extremely rare. Soft tissue $\mathrm{HC}$ occurs in $2.3 \%$ of cases and is secondary to involvement of other structures. ${ }^{[3]}$ Structures immune to development of $\mathrm{HC}$ include hair, teeth, and nails. ${ }^{[3]}$ Primary subcutaneous HC is very rare ${ }^{[1-5]}$ and primary subcutaneous implantation $\mathrm{HC}$ is unknown.

\section{CASE REPORT}

A 55-year-old female patient presented to the hospital outpatient department with a swelling in the right upper abdomen since 1.5 year. It was the size of a pea to start with and has increased in size over the last 1 year. It was nontender without any associated symptoms. The patient underwent uneventful open cholecystectomy for symptomatic cholelithiasis 2 years ago in a different hospital located in an endemic zone for hydatid disease. Her bladder and bowel habits were normal.

\section{Utpal De, Ujjal Parui}

Department of Surgery, Medical College Hospital, Kolkata, West Bengal, India

Address for the Correspondence: Dr. Utpal De, L-4/9, Phase - 3, Dankuni Housing Complex, Dankuni, Hooghly-712 311, West Bengal, India.

E-mail: Utpalde@Vsnl.Net

\begin{tabular}{|l|}
\hline Access this article online \\
\hline Website: www.ijmedph.org \\
\hline DOI: 10.4103/2230-8598.127177 \\
\hline Quick response code: \\
\hline
\end{tabular}

General physical examination was within normal limits. Abdominal examination revealed, $8 \mathrm{~cm}$ by $5 \mathrm{~cm}$ globular, nontender, mobile, well-defined, smooth, cystic mass in the right hypochondrium encroaching into the epigastrium and umbilical region [Figure 1]. The overlying skin was shiny and free from the swelling. An upper right paramedian, linear, healthy $7 \mathrm{~cm}$ scar from previous cholecystectomy was noted. The lump became prominent on straight leg and head rising. There was no cough impulse and the mass did not subside on lying down. The swelling did not have any expansile or transmitted pulsation. Percussion over the swelling was dull and auscultation did not reveal any murmer. Her hernial sites were normal. There was no regional lymphadenopathy. Perrectal and per-vaginal examination was within normal limits. Examination of the other systems did not reveal any significant abnormality.

Keeping into consideration the wide range of parietal cystic swellings, the patient was investigated. Her baseline hematological examination was normal except a raised eosinophil count (10\%). Liver function was normal and viral serological markers were nonreactive. Chest rhoentgenogram and electrocardiogram (ECG) was within normal limits. Abdominal sonography revealed a thick-walled cystic lesion in the anterior abdominal wall (size $10 \mathrm{~cm} \times 8 \mathrm{~cm}$ ) in subcutaneous plane with daughter cyst and scolices [Figure 2]. The rest of the sonography report was normal. Guided-needle aspiration revealed straw colored fluid. Chemical and pathological examination did not reveal any pathology. Microscopical examination of smear prepared from the aspirated fluid revealed scolices and a diagnosis of $\mathrm{HC}$ was made. Serological test for Echinococcus was done but was found to be negative. The precholecystectomy sonography was reviewed which revealed cholelithiasis and fatty liver with no evidence of any such lesion in other organs. On further enquiry at the hospital where the patient had 
undergone cholecystectomy it was revealed that on that particular date prior to her cholecystectomy another patient had undergone operation for liver hydatid.

At operation, the entire cyst along with the germinative membrane was removed and sent for histopathology [Figure 3]. The postoperative period was uneventful and the patient was discharged on the $10^{\text {th }}$ postoperative day after stitch removal. Histopathology was consistent with HC [Figures $4 \mathrm{a}$ and $\mathrm{b}]$. The patient was put on albendazole $(15 \mathrm{mg} / \mathrm{kg})$ in divided doses for 3 months. At 6 months follow-up the patient is doing well and no sign of recurrence could be detected by physical examination and imaging.

\section{DISCUSSION}

Subcutaneous HC may be secondary or primary. ${ }^{[1-5]}$ In secondary cysts, there is an evidence of primary location in some other organs like liver or lung. Primary subcutaneous HC are rare. In our case, the $\mathrm{HC}$ was located subcutaneously, there was no past history of previous surgery for $\mathrm{HC}$, and no HC was found in any other organs. Therefore, our patient was diagnosed as having primary subcutaneous HC.

The mechanism of primary subcutaneous localization is unclear. ${ }^{[6,7]}$ The two proposed mechanism include systemic dissemination via

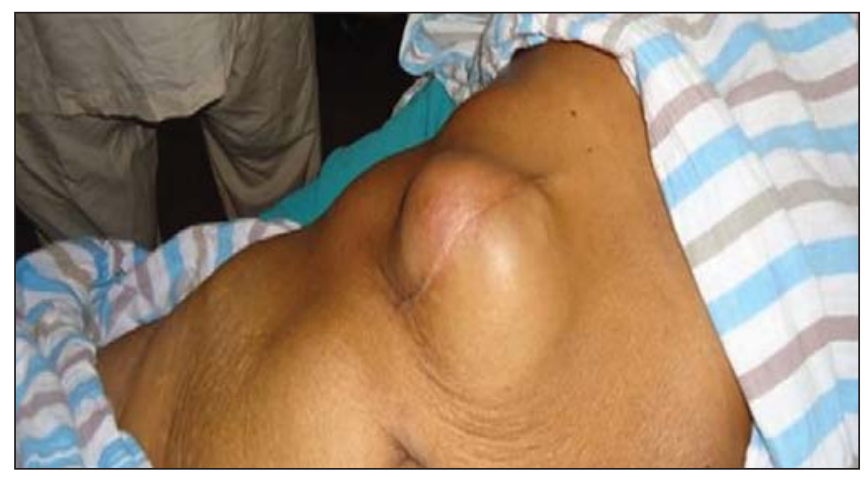

Figure 1: Preoperative photograph showing the abdominal swelling and previous cholecystectomy scar

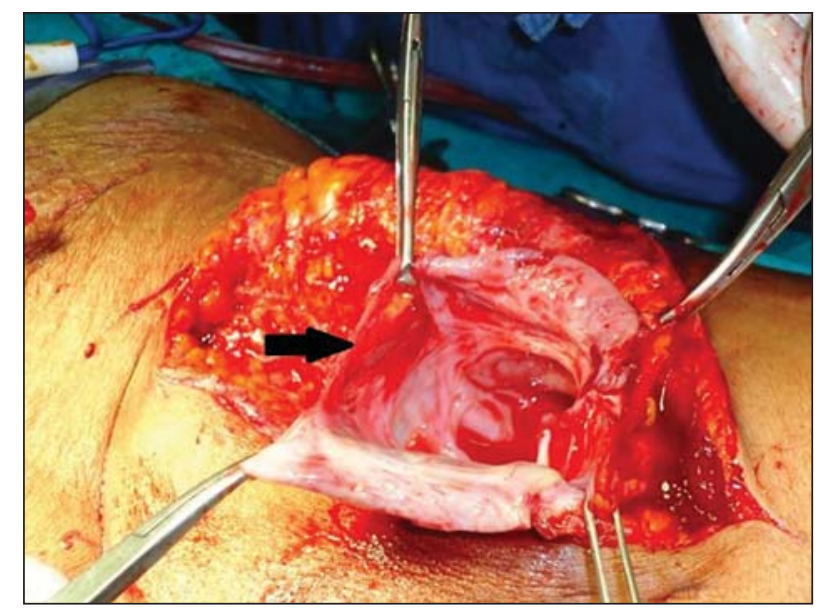

Figure 3: Peroperative photograph showing the open cyst lined by germinative membrane lymphatic route and direct spread. Direct spread may occur from inoculation (wasp bite ${ }^{[8]}$ or implantation of daughter cyst due to improper sterilization of contaminated instruments and drapes.

Symptoms are nonspecific and depend on the site of involvement, size, and the pressure effects due to the enlarged cyst. ${ }^{[1-7]}$ Signs include an inert, painless, and noninflammatory mass. ${ }^{[1-7]}$ At times the cyst may get superinfected or cracked and may simulate an abscess or a cancer. ${ }^{[7]}$

Radiological imaging is useful for diagnosis, showing the size, location, relationship to adjacent organs, and type of the cyst. It can also be used to investigate other organ involvement. ${ }^{[1-8]}$

Serology is a useful tool for the diagnosis. ${ }^{[1-7]}$ However, it is rarely positive for cysts in extrahepatic and extrapulmonary locations. ${ }^{[8]} \mathrm{It}$ is often associated with false-negative and false-positive results. ${ }^{[8]}$

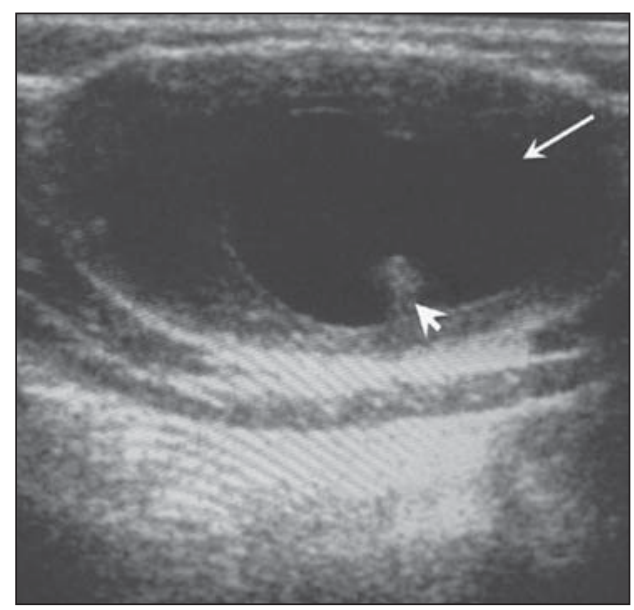

Figure 2: Sonography depicting parietal cyst with daughter cyst and scolices

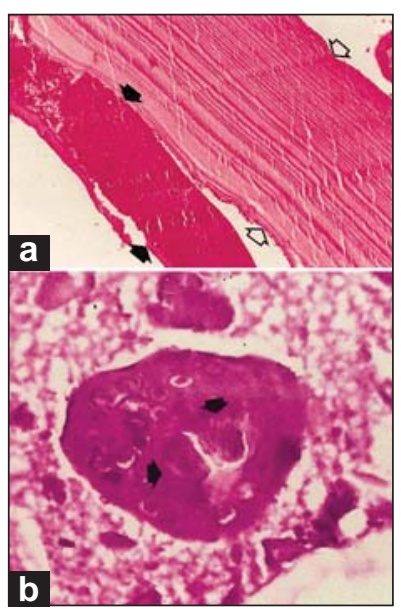

Figure 4: (a) Photomicrograph (hematoxylin and eosin stain ( $\mathrm{H}$ and $\mathrm{E})$; original magnification, 100x) of subcutaneous hydatid cyst shows a nonnucleated laminated membrane composed of innumerable delicate laminations (open arrows) and a nucleated inner germinative membrane (solid arrows). (b) High-power photomicrograph (H and E; original magnification, $\times 400$ ) of the cyst clearly depicts Echinococcus granulosus scolex with shark tooth hooklets (arrows) floating in proteinaceous cyst fluid 
Therefore in endemic zones, awareness of the physician complimented with radiological and serological investigations remains the mainstay of preoperative diagnosis particularly for the unusual presentation of the disease.

Preoperative diagnosis of subcutaneous $\mathrm{HC}$ is also possible by fine needle aspiration cytology (FNAC). ${ }^{[2,3,6,7]}$ The presence of diagnostic hooklets ensures correct identification, as in our case. No urticaria or anaphylactic reactions have been reported as a complication of this procedure.

Differential diagnosis of subcutaneous HC includes teratoma, abscess, or fibromatosis. ${ }^{[7]}$ Subcutaneous HC do not attain big size unless there is penetration to deeper layers. ${ }^{[8]}$

The treatment of choice is total surgical excision (cystectomy). ${ }^{[1-8]}$ Incidentally, subcutaneous cysts are more prone to rupture. In such a situation, the fluid contents should be removed, the laminated membrane excised, and the cyst irrigated with protoscolicidal solution. Other options include percutaneous treatment under ultrasound guidance with needle aspiration and irrigation of scolicidal solutions, as well as medical treatment with the use of albendazole. ${ }^{[1-8]}$ These drugs play an important role, preoperatively for sterilization of the cyst and postoperatively in case of spillage. Follow-up of these patients should include clinical, radiological, and serological measures for identifying recurrence of the cyst..$^{[1-8]}$

Our hypothesis of primary implantation subcutaneous HC was based on the following facts, (a) the patient hailed from an endemic zone, (b) past history of open cholecystectomy with no evidence of HC at that time, (c) a review of the list of operations performed at the place of open cholecystectomy revealed operation for liver hydatid on another patient prior to open cholecystectomy on this patient, (d) development of the cyst 6 months post-cholecystectomy in the vicinity of incision line, (e) no evidence of cyst in any organs other than the current location, and (f) the possibility based on review of literature reporting development of subcutaneous $\mathrm{HC}$ following wasp sting. ${ }^{[8]}$

\section{REFERENCES}

1. Prousalidis J, Tzardioglou K, Sgouradis L, Katsohis C, Aletras H. Uncommon sites of hydatid disease. World J Surg 1998;22:17-22.

2. Ok E, Sözüer EM. Solitary subcutaneous hydatid cyst: A case report. Am J Trop Med Hyg 2000;62:583-4.

3. Safioleas M, Nikiteas N, Stamatakos M, Safioleas C, Manti $\mathrm{CH}$, Revenas $\mathrm{C}$, et al. Echinococcal cyst of the subcutaneous tissue: A rare case report. Parasitol Int 2008;57:236-8.

4. Dirican A, Unal B, Kayaalp C, Kirimlioglu V. Subcutaneous hydatid cyst occurring in the palm and the thigh: Two case reports. J Med Case Rep 2008;2:273.

5. Oztürk S, Devec M, Yildirim S. Hydatid cyst in the soft tissue of the face without any primary. Ann Plast Surg 2001;46:170-3.

6. Ousadden A, Elbouhaddouti H, Ibnmajdoub KH, Mazaz K, Aittaleb K. A solitary primary subcutaneous hydatid cyst in the abdominal wall of a 70-year-old woman: A case report. J Med Case Rep 2011;5:270.

7. Chevalier X, R homouni A, Bretagne S, Martigny J, Larget-Piet B. Hydatid cyst of the subcutaneous tissue without other involvement: MR imaging features. AJR Am J Roentgenol 1994;163:645-6.

8. Battyany I, Andrea L, Nagy KK. Subcutaneous hydatid cyst in the popliteal fossa at the site of a previous wasp sting. Diagn Interv Radiol 2011;17:163-5.

How to cite this article: De U, Parui U. Primary subcutaneous implantation hydatid cyst. Int J Med Public Health 2014;4:137-9.

Source of Support: Nil, Conflict of Interest: None declared. 